\title{
O design como ferramenta nas políticas públicas
}

\author{
Design as a tool in public policies
}

LOBATO, Fernanda Hoffmann; Msc.; Universidade Federal do Rio Grande do Sul

fernanda.lobato@ufrgs.br

DA SILVA, Tânia Luisa Koltermann, Dra.; Universidade Federal do Rio Grande do Sul

tania.koltermann@ufrgs.br

\section{Resumo}

A preocupação com a inclusão digital esteve presente desde o início das políticas de governo eletrônico. Passadas mais de duas décadas, políticas e programas permitiram a inserção de cerca da metade dos brasileiros. Mas, assim como antigos problemas permaneceram, novos desafios surgiram. A inclusão digital vai além de fornecer o acesso à Internet e o avanço da digitalização, sem pensar no seu impacto no dia-a-dia das pessoas, pode ampliar fatores de exclusão, ao invés de diminuí-los. O presente artigo visa explorar as possibilidades de atuação do design como ferramenta de política pública, contribuindo para a inclusão das pessoas no meio digital.

Palavras Chave: Design, Inclusão digital; Letramento; políticas públicas.

\section{Abstract}

Concern with digital inclusion was a factor since the inception of the electronic government policies. Over two decades policies and programs allowed the access of roughly half of the Brazilian population and, as much as old issues remained, new challenges arose. Steadily researchers discovered that digital inclusion goes beyond providing Internet access and that the digital medium can exacerbate exclusion factors, instead of lessening them. This article aims to explore the possibilities of design as a tool of public policy, contributing to the digital inclusion.

Keywords: Design, Digital Inclusion; Literacy; Public Policies .

\section{Introdução}

O Brasil possui hoje cerca de $61 \%$ de brasileiros com acesso a Internet, com cerca de $54 \%$ de domicílios conectados. Mas o acesso não se dá de forma uniforme em todas as camadas sociais da população. O acesso é uma realidade entre as classes A e B com quase 100\% de domicílios conectados. Mas nas classes mais baixas, mais da metade das pessoas não está conectada, o que representa quase a metade do total de domicílios brasileiros (CGI, 2017).

A inclusão digital é conceituada como o acesso de comunidades em situação de desvantagem - social, econômica, geográfica, física, educacional - aos artefatos tecnológicos (dispositivos digitais e meios de conexão) e aos bens simbólicos (apps, softwares, sites, redes sociais) relacionados às TIC. A inclusão digital têm implicações sociais importantes, podendo reduzir as desigualdades e ampliar as possibilidades de diálogo, aprendizado e participação, 
contribuindo para a construção de um mundo mais justo. No entanto, a inclusão digital também pode aprofundar, ao invés de diminuir, a exclusão social (DEURSEN et al., 2017, UNESCO, 2017).

A inclusão e a exclusão não são conceitos opostos, não sendo definidos apenas pelo pela presença ou falta de acesso. Possuem uma relação complexa que envolve diversos fatores, como a qualidade de acesso e o impacto na qualidade de vida. (BUZATO, 2007; HELSPER, 2016).

De acordo com HELSPER (2016) e Deursen et al. (2017), as pesquisas sobre o tema tem trabalhado com três níveis de exclusão. O primeiro nível é a presença, o acesso. O segundo nível desdobra-se em quatro fatores: qualidade do acesso, motivação, habilidades e uso.

O terceiro nível se traduz em como a pessoa obtém resultados tangíveis em sua vida através do acesso à Internet. Benefícios como, por exemplo, conseguir um emprego (HELSPER, 2016; DEURSEN et al., 2017; UNESCO, 2017). Até o momento as iniciativas de inclusão, tanto públicas quanto privadas e terceiro setor, têm trabalhado prioritariamente com os dois primeiros níveis, através de políticas de promoção do acesso e de letramento digital.

Essa exclusão de terceiro nível, a falta de percepção de valor da Internet como uma ferramenta que traria benefícios a rotina diária, pode ser percebida pela baixa adesão a serviços públicos por meios digitais. Serviços públicos digitais são o conjunto de ações do Estado que envolvem interação em meios digitais, para obtenção de direito e cumprimento de deveres, tendo que ter um resultado percebível e tangível pela população (BRASIL, 2016).

No Brasil, como em outros países, a adesão a versão digital de um serviço público é baixa em relação ao acesso à Internet ou a sua versão "tradicional". Por exemplo, no Reino Unido, dados do GOV.UK, mostram que $74 \%$ das pessoas usam a Internet para fazer seguro do seu carro, mas apenas 51\% pagam o "car tax" (equivalente ao IPVA) pelo serviço público digital (SARGEANT, 2013). A compreensão e entendimento desse fenômeno e das suas causas é fundamental para o desenvolvimento de políticas que, de fato, a inclusão digital beneficie a todos.

Há indícios de que além da capacitação, do letramento da população, há uma lacuna do que é oferecido hoje em serviços públicos digitais e a real demanda da sociedade. Dados da TIC Governo Eletrônico realizada pelo CGI.Br em 2010, apontam que 85\% dos entrevistados concordam que "o governo tem que ensinar as pessoas usarem os serviços públicos pela Internet". A mesma pesquisa aponta como fatores limitadores da interação das pessoas com o governo eletrônico na Internet: a preocupação com a segurança, a dificuldade de encontrar os serviços, de interagir com os mesmos e o desconhecimento da existência do serviço (CGI, 2011).

A medida que nossa sociedade se transforma, o design segue o fluxo. 0 advento das plataformas digitais desencadeou uma reavaliação das práticas e procedimentos educacionais, bem como dos conceitos filosóficos que há muito definiram e enquadraram a atividade de design. As mudanças nas indústrias, a globalização e a digitalização, afetaram os papéis dos designers e resultou em mudar o papel dos designers de criadores para agentes de inovação, e de coordenadores e co-criadores, para construtores de capacidades (HELLER e TALARICO 2011; 
NORMAN, 2016; MIETTINEN E SARANTOU, 2017).

O desenho de uma política pública é uma das possíveis atribuições do Design (MAFFEI, MORTATI, VILLARI, 2013). O campo do design modifica-se, seguindo as mudanças e as demandas de nossa sociedade. Qual seria o papel do design na promoção da inclusão digital? Talvez a resposta mais óbvia seja o desenvolvimento de recomendações, a usabilidade e a acessibilidade. Mas algumas iniciativas vêm mostrando que o design pode ser uma ferramenta valiosa na construção de políticas públicas. Nesse cenário, o presente artigo explora políticas públicas onde o design pode ser uma ferramenta para o desenvolvimento de ações que promovam a inclusão digital para os níveis além do simples acesso, através de processos e metodologias como o design participativo.

Esse artigo está organizado da seguinte forma: a primeira parte apresenta conceitos de políticas públicas inclusão digital e letramento. A segunda parte apresenta como as mudanças da sociedade abrem novos campos de atuação para o design seguida de um capítulo sobre como o design se articula com as políticas públicas e onde ele se encontra incluído nos processos de políticas públicas brasileiros e, por fim, é apresentada uma pequena amostra de iniciativas onde o designer poderia atuar na estrutura da política.

\section{Inclusão digital e letramento}

A partir de 1995, com a liberação da Internet comercial, a participação na Sociedade da Informação passou a ser uma possibilidade real para o Brasil. Da criação das primeiras redes, ainda na década de 70 , para a manutenção das redes de contato dos exilados políticos que preparavam sua volta ao Brasil, ao debate dos direitos civis no meio digital, o qual resultou na promulgação do Marco Civil da Internet em 2014, o Brasil tem se colocado como pioneiro nas iniciativas de inclusão e direitos civis na Internet (CARVALHO, 2006, ROVAI, 2014, BRASIL, 2015b).

No Brasil a inclusão digital desenvolveu-se no âmbito do Programa de Governo Eletrônico, em paralelo aos programas de combate a desigualdade social como o Bolsa-Família. O Programa de Governo Eletrônico brasileiro - GOV.BR, foi criado no 2000 a partir de um Grupo de Trabalho Interministerial com a finalidade de examinar e propor políticas, diretrizes e normas relacionadas às novas formas eletrônicas de interação. O decreto de 18 de Outubro de 2000 instituiu o Comitê Executivo de Governo Eletrônico - CEGE, que tinha por função formular políticas, estabelecer diretrizes, coordenar e articular as ações de implantação do Governo Eletrônico. Muitas dessas ações já existiam, mas estavam fragmentadas e descentralizadas (BRASIL, 2015a).

Em 2002 o CEGE foi reformulado e definiu diretrizes gerais para o Programa de Governo Eletrônico, dentre elas a que a promoção da Cidadania e de que Inclusão Digital eram indissociáveis do Governo Eletrônico. Em 2004, parâmetros para a oferta de serviços públicos e de como o governo deveria atuar na promoção do acesso e universalização foram definidos. Os parâmetros priorizavam os serviços básicos, que atendessem amplas parcelas da população, preferencialmente as classes C, D, e E. Os sítios e serviços deveriam ser inclusivos e não 
excludentes, atendendo pessoas com deficiência, baixa escolaridade. Deveriam também funcionar em diversas plataformas e dispositivos. Em 2003, o Decreto de 29 de Outubro, instituiu os Comitês Técnicos do Comitê Executivo de Governo Eletrônico, dentre estes, o Comitê Técnico de Inclusão Digital (BRASIL p.9, 2004; BRASIL, 2015a).

Em cerca de uma década, essas políticas e programas permitiram a inserção de cerca da metade dos brasileiros. Mas, embora o Brasil tenha avançado na inclusão digital, esse avanço ocorreu em ritmo mais lento que o esperado pelos especialistas. Ainda permanecem desigualdades marcantes quanto ao uso da Internet.. Entre os motivos apontados está o abandono gradual, nos últimos anos, da ampliação do Plano Nacional de Banda Larga (PNBL) e das demais políticas públicas inclusivas. Atualmente, Chile, Argentina, Uruguai, Venezuela e Colômbia têm proporcionalmente mais cidadãos com acesso a internet do que o Brasil. Atualmente no Brasil não há uma política única e integrada de inclusão digital, existindo diversos programas que coexistem de forma independente e desarticulada (ROVAI 2014; TCU, 2015; CGI 2016).

Prevista nos documentos iniciais do governo eletrônico brasileiro, a preocupação com a inclusão e a promoção de uma educação digital, desapareceu nos documentos atuais. A EGD - o último documento referência do governo federal na área, apresenta a inclusão digital como um desafio a ser enfrentado, mas no papel de apoio de outras políticas públicas, não como um objetivo do próprio programa. Não há comprometimento com desenvolvimento de serviços voltados às classes mais baixas, ou ações de formação e letramento (BRASIL, 2016).

A necessidade de ações de formação e letramento pode ser percebida em dados como os levantados pela TIC Governo Eletrônico realizada pelo CGI.Br em 2010, onde 85\% da população em geral consultada e $92 \%$ dos usuários de e-gov concordam que "o governo tem que ensinar as pessoas usarem os serviços públicos pela Internet". A mesma pesquisa aponta como fatores limitadores da interação das pessoas com o governo eletrônico na Internet: a preocupação com a segurança, a dificuldade de encontrar os serviços, de interagir com os mesmos e o desconhecimento da existência do serviço (CGI.Br, 2011).

Quando falamos apenas em níveis secundários e terciários, como habilidades, uso e motivação, a desigualdade se acentua, sobretudo com relação ao uso de serviços públicos: enquanto $80 \%$ das pessoas com Ensino Superior utilizam serviços públicos digitais, apenas $36 \%$ e $64 \%$ das pessoas com ensino fundamental e médio o fazem. Se o extrato for a renda, apenas $52 \%$ dos indivíduos com ganho familiar de até dois salários mínimos utilizam o governo eletrônico (CGI, 2017). Pesquisas mostram que, no Brasil, a falta de habilidade com computador é a razão para 74\% das pessoas no Brasil nunca terem utilizado a Internet (CGI 2016).

Cerca de $24 \%$ da população brasileira possui algum tipo de limitação física ou deficiência, $9,6 \%$ da população é analfabeta e $7,4 \%$ da população tem 65 anos ou mais. Cerca de $50 \%$ de pessoas da classe $\mathrm{C}$ consideram que usar a Internet para o governo é complicado e $61 \%$ preferem fazer contato pessoalmente. Nas classes D e E esses números aumentam para $64 \%$ e 60\% (IBGE, 
2010; CGI, 2017).

O relatório da Unesco (p. 17, 2017) aponta que, na América Latina, a razão fundamental para uma parcela considerável dos habitantes e empresas da região permanecerem desconectados, em regiões que já contam com infraestrutura, são o preço e o fato dos serviços serem considerados irrelevantes. O fato dessa parcela da população considerar um serviço público irrelevante pode estar associado ao fato de não ver suas necessidades atendidas no conjunto de serviços disponíveis. Ou, caso encontre um serviço que the seja útil, a necessidade de inserção de dados pessoais, associado ao baixo letramento, suscite dúvidas acerca da segurança, confiança da aplicação. Ou, que ele fará algo "errado" que impedirá de obter o serviço.

A falta de habilidades, em conjunto com outros fatores, pode ser a causa de que uma parcela da população, principalmente a mais vulnerável, não se beneficie do acesso ao meio digital, em especial para cumprir seus deveres e obter seus direitos.

O letramento, ou a falta dele, pode ser usado como uma ferramenta exclusão, de controle social e de restrição de acesso. Um exemplo é a lei de americana de imigração de 1917, conhecida como Literacy Act ou Asiatic Barred Zone Act, que restringia, ao invés de regular, a imigração nos Estados Unidos. A lei impôs testes de alfabetização aos imigrantes, criou novas categorias de pessoas inadmissíveis e proibiu a imigração da Zona Ásia-Pacífico. A lei foi revogada apenas em 1952 (HELSPER, 2016; UNESCO, 2017).

O letramento digital é o domínio do conjunto de informações e habilidades para o uso das TIC que permite que as pessoas alcancem resultados concretos e de qualidade em sua vida cotidiana. É a capacidade para ler e interpretar a mídia, reproduzir, avaliar e aplicar novos conhecimentos adquiridos em ambientes digitais. Outros termos como alfabetismo digital também são encontrados, com significado similar. O letramento digital prescinde apoio técnico e emocional, orientação e está sujeito aos contextos de aprendizagem (XAVIER, 2007; HELSPER, 2016). Considera-se que a pessoa está plenamente incluída se seu letramento digital resulta em benefícios tangíveis na vida cotidiana.

\section{Novos campos do design}

Desde o advento da Internet, da proliferação das tecnologias digitais a partir da década de 90, uma crescente variedade de campos de design despontaram: design de navegação, design de eventos, design generativo, design de cenário, design de invenção, design de experiência, design de experiência de usuário, design humanitário, design de interação, design de interface, design emocional, design de serviço e design social, para citar alguns (ICOGRADA, 2011).

As discussões sobre o papel do Design na sociedade vêm se intensificando à medida que o tema tem aparecido com mais frequência em publicações nacionais, cursos de graduação e pós-graduação. As organizações e conselhos de design internacionais tem acompanhado essas mudanças, alterando seus manifestos e definições acerca da profissão. 
A International Council of Design - ico-D e World Design Organization - WDO, demonstram preocupações com os impactos sociais e ambientais. Para o ico-D (2013), antigo ICOGRADA, o designer deve compreender o impacto cultural, ético, social, econômico e ecológico de seu trabalho. Já a WDO (2015), antiga ICSID, preconiza que os designers industriais devem ser pragmáticos, colocando o ser humano no centro do processo e serem empáticos, com uma compreensão profunda da necessidades dos usuários. Já American Institute of Graphic Arts AIGA, apesar de reformular suas definições, em seu conceito escrito por Cezzar (2015), atém-se a tentar contextualizar o trabalho do designer gráfico entre os meios físicos e virtuais.

A preocupação em como o design age sobre a sociedade também é expressa em vários manifestos de profissionais da área. O site Social Design Notes coletou cerca de 100 manifestos ao longo de mais de 100 anos. Entre estes, as três versões de First Things First de 1964, 2000 e 2014, que expressam a insatisfação com o design sendo ferramenta de práticas daninhas do mercado, da deterioração do meio-ambiente e da vida das pessoas. Os manifestos pedem a prioridade das formas de comunicação mais duradouras e democráticas, colocando o ser humano e o meio-ambiente em primeiro lugar (SOCIAL DESIGN NOTES, 2014).

O design é uma atividade que influencia e é influenciada pelo equilíbrio de interesses entre diferentes grupos sociais que participam do processo e lidam com objetos ou sistemas. Em plena revolução Russa, o discurso marxista influenciou a Associação Alemã de Artesãos, que acreditava que o design seria uma ferramenta para superar todos os conflitos de classe. Walter Gropius, participante da associação e fundador da Bauhaus, acreditava que a produção industrial seria capaz de reduzir as diferenças de classes (COUTO e RIBEIRO, 2002; PORTINARI E NOGUEIRA, 2016).

$\mathrm{O}$ design está ligado à política desde suas raízes. O design não pode ser considerado socialmente neutro. Mesmo quando colocado como uma ciência neutra, o design tem responsabilidades com o indivíduo. De acordo com Lobach (1976 p.14, 2000), o design pode ser colocado como "defensor dos interesses do usuário". Para o autor, o design seria o processo de adaptação do ambiente "artificial" às necessidades físicas e psíquicas dos homens na sociedade.

\section{Políticas para o design e design para as políticas}

Políticas públicas são meios de atuação de um governo em relação a temas de interesse público, como saúde, habitação. As políticas públicas se materializam através de programas, subsídios governamentais, rotinas administrativas, decisões, podendo estar amparadas por leis ou normativos menores como decretos, portarias e instruções normativas. Uma política pública norteia as iniciativas de fomento, com objetivos, atores envolvidos, ações, assim como metas e indicadores de acompanhamento (MAFFEI, MORTATI, VILLARI, 2013).

Políticas públicas fazem parte do sistema de funcionamento de qualquer governo, sendo formuladas a partir do Plano de Governo definido pelo poder executivo. Políticas públicas são executadas a partir de uma série de ações, como iniciativas e programas, apresentando metas e objetivos. Possuem redes dinâmicas de muitos atores, que atuam em paralelo em relações 
complexas. Sua formulação resulta em uma série de subprocessos inter-relacionados que formam um ciclo contínuo, indo do planejamento até sua avaliação (MAFFEI, MORTATI, VILLARI, 2013).

Desde o século XIX, o design é reconhecido por governos como um fator de importância para gerar desenvolvimento. Em 1944, ao final da guerra, o Reino Unido implementou políticas que utilizavam o design como ferramenta com o objetivo de estimular o crescimento do país. $\mathrm{Na}$ década de 70, as Nações Unidas recomendou que países em desenvolvimento adotassem políticas em design para desenvolver a economia e a indústria. Em 1973, o primeiro programa nacional de desenvolvimento científico e tecnológico identificou design como área potencial (PATROCíNIO, 2013).

No Brasil, a presença do design no setor público é pontual, parcialmente atribuída a industrialização tardia. São raros e isolados os casos onde os designers foram chamados para apoiar iniciativas na sociedade brasileira. Em 1995 foi lançado o Programa Brasileiro de Design, no entanto a proposta era de delegar à iniciativa privada grande parte das responsabilidades sem, no entanto, criar um conselho de design atuante. O programa acabou ficando somente no papel (LEON E MONTMORE, 2008, PATROCÍNIO, 2013).

Por políticas públicas de design entende-se os princípios estabelecidos pelo governo para fazer uso do design como ferramenta estratégica de desenvolvimento social, econômico, industrial e regional (PATROCÍNIO, 2013). Aqui cabe um esclarecimento sobre o assunto. Podemos dividir as ações de governo nesse âmbito em políticas públicas para o design e design para as políticas públicas:

O primeiro campo são as ações do governo para fomento do design na área privada, principalmente como fomento ao P\&D. Atualmente no governo brasileiro o design vem recebendo iniciativas nesse âmbito, mas sem uma coordenação centralizada. Em 2014, dois ministérios, o Ministério da Indústria e Comércio e do Ministério da Cultura inseriram o design em suas agendas. Ambos lançaram documentos de diagnóstico do design Brasileiro.

O diagnóstico do Ministério de Desenvolvimento, Indústria e Comércio Exterior - MDIC (BRASIL, 2013), desenvolvido em conjunto com o Centro Brasil Design e Apex Brasil, apresenta-se como um "levantamento do estado da arte do design brasileiro", para o fortalecimento do setor e servir de base para elaboração de ações e políticas públicas voltadas ao desenvolvimento da competitividade industrial tendo o design como fator estratégico. Já o diagnóstico do Ministério da Cultura - MINC (BRASIL, 2014a), realizado de forma colaborativa como insumo para o Plano Setorial de design é relativamente menor e menos completo que o do MDIC. Ambos os documentos são voltados para o mercado, sem entrar no papel do design como ferramenta nas políticas públicas.

Já o design para as políticas públicas é o campo onde o design age como elemento viabilizador de uma política pública.

\subsection{Design como ferramenta de políticas públicas}


Para Maffei, Mortati e Villari (p.2 2013) a construção de uma política é igual a uma intervenção de design estratégico, sendo a construção de uma política um dos possíveis objetos do processo de design. No design em políticas públicas três abordagens parecem sobressair-se das demais: design social, design thinking e design de serviços.

No Brasil, o design social tem suas raízes no Brasil na década de 60, na Escola Superior de Desenho Industrial (ESDI) com um viés dos designer egressos de Ulm como Alexandre Wollner. Na década de 80 os profissionais formados pela ESDI e a APDINS-RJ pautavam-se na prática de "atuar no e sobre o mercado" . O designer deveria conscientizar seu cliente sobre as consequências sociais positivas ou negativas que sua demanda poderia gerar, dependendo do rumo e das intenções do projeto. O design social também é chamado de design participativo, co-design ou design em parceria. Existem algumas diferenças entre os termos utilizados e as práticas, mas o ideal democrático é o mesmo (YAMAMOTO, 2014; JUDICE, 2014).

Para Maffei, Mortati e Villari (2013) para se aplicar o conceito de design participativo em políticas públicas deve-se observar que:

- os problemas a serem considerados para a participação dos cidadãos na formação de políticas através do design;

- a inclusão de abordagens de co-design para a formulação de políticas;

- a possibilidade de incluir processos participativos no campo emergente das políticas de design.

A ideia de formulação de políticas colaborativas é proposta tanto para o desenvolvimento de políticas (campo geral,) como na formulação de políticas de design através de práticas colaborativas (campo disciplinar).

No final dos anos 2000 o conceito de design social ganhou força. Possivelmente por fatores externos, como a crise financeira de 2008, que levou designers a buscar o setor público e de organizações não governamentais como clientes potenciais. O foco de fabricação tradicional do mercado de design, em muitas áreas-chave, tornou-se menor e mais concentrado, já a pesquisa de design deu aos designers novas ferramentas para ajudá-los a trabalhar com entidades abstratas, como serviços e comunidades, em vez de apenas com as coisas (CHEN ET AL, 2015).

Já as abordagens de design thinking e design de serviços aparecem mais entrelaçadas. No entanto pode-se dizer que, enquanto o design thinking é uma abordagem, o design de serviços é uma metodologia, sendo o objetivo desse último "transformar o serviço entregue em algo útil, utilizável, eficiente, eficaz e desejável". O uso de design Thinking parece ser uma tendência em governos do mundo todo (Design Council, 2013).

Em 2013, o Design Council, com o apoio da Comissão Europeia, lançou o relatório Design for Public Good (Design para bem público), onde define uma Escala da presença do Design no Setor Público (Fig. 1) para ser utilizada como ferramenta de diagnóstico e roteiro para inserção do design nas políticas públicas (Design Council, 2013). 
Figura 1- Escala de design no setor público

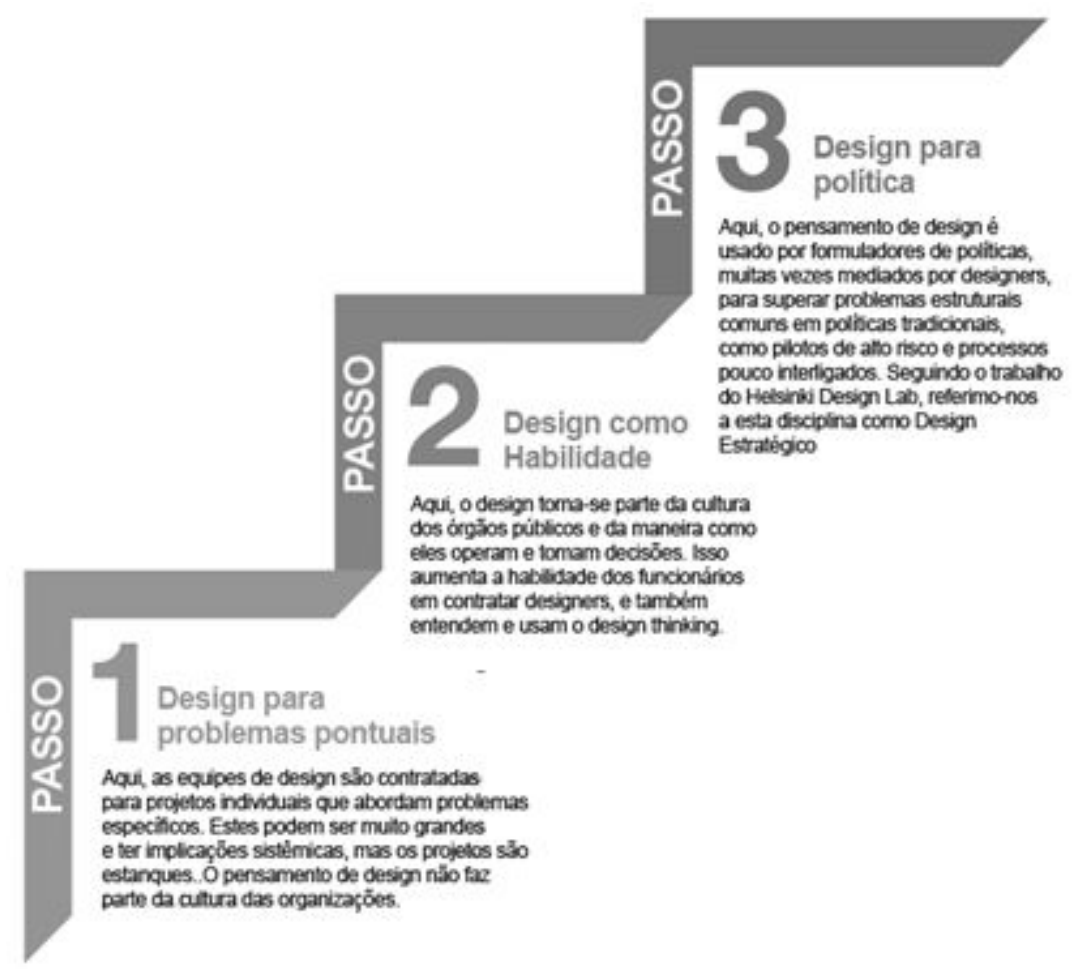

Fonte: Design Council (2013) , tradução própria

O documento utiliza o design thinking e o design de serviços, mas passa por áreas diversas como o design centrado no Humano - DCH e Experiência do usuário - UX.

Além de recomendar o uso da Escala para diagnóstico e roteiro para acompanhamento das ações, o documento também recomenda a construção de uma filosofia de design dentro do governo, com um setor de design forte e atuante que possa oferecer o desenho de estratégias e desenho de serviços para o setor público e, por fim, construir indicadores de impacto para medir a inovação proporcionada ao setor público.

No Brasil, o papel do design no setor público ainda é um assunto pouco discutido. De acordo com Hobi (2015 pág. 34) em sua análise a partir da Escala Design para o Setor Público, o país está no nível 1 da Escala, onde o governo contrata pontualmente consultorias de design para solucionar problemas no setor público. Assim não há mudanças desde que Montmore e Leon (p.62-86, 2008), historiaram a presença do design nas políticas públicas no Brasil. Em sua análise de cerca de 50 anos de design, o uso do design em iniciativas públicas é esporádico. Alguns marcos merecem menção como em 1975, quando foi instalado no Instituto Nacional de Tecnologia - INT, um grupo de designers e engenheiros que devia dar apoio a os projetos tecnológicos oficiais. No início da década de 80, o INT estava vinculado a programas estratégicos governamentais.

São dessa época: as identidades visuais de empresas públicas como Itaipu e Petrobrás desenvolvidas entre 1966 e 1974 pelo PVDI, estúdio de Aloísio Magalhães. o mobiliário urbano dos 
vagões de metrô do Rio e São Paulo, desenhados pela equipe de Roberto Verschleisser entre 1974 e 1979, o "orelhão" de Chu Ming Silveira desenvolvido em 1971 e o redesenho da Avenida Paulista pelo estúdio Cauduro \& Martino em 1973. Este último, que mudou dramaticamente a configuração da região, foi feito sem participação popular. Dos projetos citados, nenhum partiu de uma iniciativa interna, todos desenvolvidos por escritórios ou agências contratadas (MONTMORE e LEON p.62-86, 2008).

\subsection{O design e o governo digital}

No entanto, pelo menos uma área do governo tem inserido, aos poucos, o design em seus processos. Desde a década de 90, algumas empresas de processamento de dados preveem vagas com o perfil de designer em seus concursos. Um exemplo é o concurso público no 24/2012 da Cia. de Processamento de dados do Estado do Rio Grande do Sul - Procergs. O concurso contou com vaga para área de design (categoria C.23/12 - Técnico de Computação - TC - Programador Visual/ Design). Dentre as atribuições estão: "Prospectar, projetar, especificar e desenvolver soluções de comunicação visual e design gráfico para atender sistemas de informação".

A inserção de designers nas companhias de processamento de dados e seu impacto no governo eletrônico ainda é uma história do design brasileiro a ser contada. A contratação de designer via concurso pode apontar que, ao contrário do que Hobi (2015) descreveu, há a possibilidade de, pelo menos quando falamos em governo eletrônico, o Brasil já esteja no passo 2 da Escala: o design como habilidade.

Como visto nos levantamentos de Maffei, Mortati e Vilari (2013), Design Council (2013) e Hobi (2015), o design vem sendo utilizado como impulsionador de políticas públicas em diversas áreas do governo. As principais abordagens: design de serviços, design participativo, design thinking, colocam o usuário-cidadão como ponto de partida, central de seus programas.

Analisando as políticas públicas de inclusão digital do governo federal, é possível verificar lacunas nas iniciativas, como a falta de iniciativas de letramento (BRASIL, 2018). Lacunas que podem ser trabalhadas estrategicamente por designers com uma perspectiva voltada ao ser humano, ao cidadão-usuário. A proposta não é esgotar o assunto, nem as iniciativas, mas apresentar algumas estruturas do governo onde o design tem um papel ainda não mapeado na inclusão digital.

O Sistema de Administração dos Recursos de Tecnologia da Informação - SISP e o Sistema de Administração dos Recursos de Comunicação - SICOM, são sistemas estruturantes orgânicos, que perpassam quase todos os órgãos do governo federal servindo de executores das políticas públicas, programas e iniciativas. Ambos os sistemas têm ações no desenho de serviços públicos, assim como interfaces com os programas de inclusão digital (CHAVES, 2015; BRASIL, 2016).

As ações são coordenadas através da Secretaria de Comunicação - SECOM e da Secretaria de Tecnologia da Informação - STI, gestoras dos sistemas SICOM e SISP respectivamente. Dentre as iniciativas estão o Modelo de Acessibilidade em Governo Eletrônico - eMAG, a Identidade digital 
de governo - IDG e a Estratégia de Governança Digital - EGD.

A EGD, como descrito antes, é o documento atual norteador das estratégias de governo eletrônico, renomeado com Governança Digital . A EGD, ao contrário do documento norteador do governo eletrônico de 2004, não prevê ações no campo da inclusão digital, ou o compromisso com o desenvolvimento de serviços para classe $\mathrm{C}$, tratando-a como um programa em separado.

O Programa de Inclusão Digital, de responsabilidade Ministério da Ciência, Tecnologia, Inovações e Comunicações - MCTIC, possui diversos projetos ligados a ampliação do acesso a rede. $O$ documento que norteia os projetos de inclusão digital é a Estratégia Brasileira para a Transformação Digital - e-Digital (BRASIL, 2018).

O documento, apesar de reconhecer a necessidade de letramento inclusive apontando o documento do TCU de 2015 e as estatísticas do CGI.Br , não apresenta nenhuma ação ou compromisso com a inclusão ou o desenvolvimento de políticas de letramento. O documento considera o cenário de inclusão até o segundo nível, sem contar o desenvolvimento de habilidades. A tradução da inclusão em benefícios tangíveis, terceiro nível, sequer é citada, mesmo como parâmetro para escolha dos serviços a serem digitalizados na plataforma digital (BRASIL, 2018).

Por fim, há a Câmara Setorial de Design no Ministério da Cultura cujo Plano Setorial Design Brasil 2026, apesar de não prever ações de inclusão digital, prevê uma inserção maior da disciplina do design nas políticas de governo (BRASIL, 2014b).

\section{Considerações finais}

Políticas claras e estruturadas são essenciais para alavancar o desenvolvimento econômico e social de todos os membros da sociedade. Como exemplo, há o programa do Reino Unido que tem por objetivo alcançar a plena capacitação digital de sua população no ano de 2020 . O plano do Reino Unido é resultante de pesquisa de campo e de consulta aos usuários, identificando os principais desafios da política e as necessidades de cada segmento do público-alvo. O plano do Reino Unido também é citado na EGD, como um modelo a ser seguido.

Atualmente existem grupos de pessoas que possuem acesso mas não se identificam no meio digital, não encontram as respostas para suas necessidades e então fazem uma subutilização do potencial da rede. A exclusão digital, ou a forma que as pessoas usam a Internet, refletem a desigualdade presente em aspectos sociodemográficos como gênero, idade, escolaridade, local de residência, classe social, deficiência, dentre outros fatores.

A inclusão, assim como o letramento, devem ter um benefício real na vida do indivíduo, mas a verificação desse benefício nem sempre é simples e o processo pode estar contaminado pelo juízo de quem já está incluído.

O design tem, historicamente, se mostrado como uma ferramenta valiosa para a promoção da cidadania e o desenvolvimento da sociedade. 
Heller e Talarico (ICOGRADA 2011 p.85) e Norman (2016), alertam para a apropriação do design por outras áreas, como a de negócios e que, portanto, cabe ao design ser fluente nessas áreas. Essa apropriação já é percebida no Brasil, onde o discurso do Design Thinking foi sendo apropriado pelas áreas de Negócios e setores de Inovação sem, no entanto, incluir o designer no processo.

De acordo com Norman (2016) o aumento da sofisticação das tecnologias para casa, negócios, educação e entretenimento, as habilidades manuais do designer já não são suficientes. Enquanto os designers permanecerem artesãos, eles podem agregar valor, mas não podem ser a liderança. Hoje, engenheiros e empresários decidem o que deve ser feito e os designers ajudam a obter os resultados, mas raramente são os líderes.

O design não possui fronteiras sólidas e consolidadas de campos onde pode agir. Nem limites na forma de agir ou construir uma solução. O design possui sim, uma construção teórica sólida e histórica que pode ser aplicada nas mais diversas situações. Para Amstel (2013), o design tem maior potencial democrático a partir de seus processos. O designer poderia ser um impulsionador de políticas públicas. Durante décadas o design tem sido visto como uma ferramenta de mercado, no entanto, igualmente antiga é a função do design como ferramenta de transformação política e social.

\section{Referências}

AMSTEL, Frederick van. 0 que o design pode fazer pela política brasileira. 2013. Disponível em: <http://www.usabilidoido.com.br/o_que_o_design_pode_fazer_pela_politica_brasileira.html>. Acesso em 4 mar. 2018.

BRASIL. Estratégia Brasileira para a Transformação Digital (e-Digital). Ministério da Ciência, Tecnologia, Inovações e Comunicações. Brasília: MCTIC, 2018. Disponível em: <http://www.mctic .gov.br/mctic/export/sites/institucional/transparencia/arquivos/Plano-de-Cidadania-Digital-Public ado.pdf >. Acesso em: 25 mar. 2018.

Estratégia de Governança Digital da Administração Pública Federal 2016- 19. Ministério do Planejamento, Orçamento e Gestão, Secretaria de Tecnologia da Informação. Brasília: MP, 2016. Disponível em: <https://www.governoeletronico.gov.br/documentos-e-arquivos/Estrategiade-Governanca-Digital.pdf >. Acesso em: 11 abr. 2017.

(2015a). Histórico do Programa de Governo Eletrônico Brasileiro. Portal de Governo Eletrônico Ministério do Planejamento . Disponível em: <http://www. governoeletronico.gov.br/ sobre-o-programa/historico>. Acesso em: 27 setembro 2017.

\section{5b). "Pioneirismo no debate sobre internet dá credibilidade ao País", diz Aldo Rebelo. <http://www.brasil.gov.br/ciencia-e-tecnologia/2015/03/ pioneirismo-no-debate-sobre-internet-da-credibilidade-ao-pais-diz-aldo-rebelo/reuniao_comite.jp g/view>. Acesso em: 27 setembro 2017.}

(2014a). Diagnóstico Setorial Design Brasil. Brasília. Set. 2014. Disponível em: 
<http://culturadigital.br/design/files/2014/09/diagonostico_rev_setembro1.pdf >. Acesso em 2 Jul 2017.

(2014b). Plano Setorial Design Brasil 2026. UNESCO/ Secretaria da Economia Criativa / Ministério da Cultura/ Colegiado de Design. Brasília. Set. 2014. Disponível em: <http://design.cnpc.cultura.gov.br/wp-content/uploads/sites/15/2016/05/PLANO-SETORIAL-DESI GN.pdf>. Acesso em 2 Jul 2017.

Diagnóstico do Design Brasileiro. Centro Brasil Design. Ministério do Desenvolvimento, Indústria e Comércio Exterior. Brasília. 2013 Disponível em: <http://www.cbd.org.br/wp-content/ uploads/2013/01/Diagnostico_Design_Brasileiro_Web.pdf >. Acesso em 4 Jul 2017.

Oficinas de planejamento estratégico: Relatório consolidado. Comitê Executivo do Governo Eletrônico. Brasília, 2004. Disponível em: <https://www.governoeletronico.gov.br/ documentos-e-arquivos/BRASIL\%20-\%202004\%20-\%20diretrizes_governoeletronico.pdf >. Acesso em: 11 mai. 2017

BUZATO, Marcelo El Khouri. Entre a fronteira e a periferia: linguagem e letramento na inclusão digital. 2007. 284p. Tese (doutorado) - Universidade Estadual de Campinas, Instituto de Estudos da Linguagem, Campinas, SP. Disponível em: <http://libdigi.unicamp.br/document/?code= vtls000415042 >. Acesso em: 29 mar. 2017.

CARVALHO, M. A trajetória da Internet no Brasil: do surgimento das redes de computadores à instituição dos mecanismos de governança. 239 p. Dissertação (Mestrado em Engenharia de Sistemas e Computação) - Universidade Federal do Rio de Janeiro, COPPE. Rio de Janeiro, 2006. Disponível em: <http://www.nethistory.info/Resources/Internet-BR-Dissertacao-MestradoMSavio-v1.2.pdf>. Acesso em: 27 set. 2016.

CEZZAR, Juliette. What is graphic design? AIGA. 2015. Disponível em: <http://www.aiga.org/guidewhatisgraphicdesign > Acesso em: 25 jan 2017.

CHEN, Dung-Sheng. Social Design: An Introduction. International Journal of Design, 10(1), 1-5. Disponível em: <http://ijdesign.org/index.php/IJDesign/article/view/2622/723>. Acesso em 4 Jul 2017.

CGI.Br. Pesquisa sobre o uso das tecnologias de informação e comunicação nos domicílios brasileiros -TIC Domicílios 2016. [livro eletrônico]. Núcleo de Informação e Coordenação do Ponto BR [editor]. São Paulo : Comitê Gestor da Internet no Brasil, 2017. Disponível em: <https://www.cgi.br/publicacao/pesquisa-sobre-o-uso-das-tecnologias-de-informacao-e-comunica cao-nos-domicilios-brasileiros-tic-domicilios-2016/>. Acesso em: 14 mar. 2018.

. Pesquisa sobre o uso das Tecnologias da Informação e da Comunicação no Brasil - TIC Governo Eletrônico 2010. São Paulo: CGI.br, 2016. Disponível em: <http://cetic.br/pesquisa/ governo-eletronico/publicacoes >. Acesso em: 18 jun. 2016.

CHAVES, Nicir. Governança Corporativa da Estratégia à Transformação dos Serviços. [apresentação]. 16으 Seminário Técnico-Gerencial promovido pela Escola Nacional de Administração Pública (Enap). 2015.Disponível em: https://pt.slideshare.net/CgceEnap/governana-corporativada-estratgia-transformao-dos-servios>. Acesso em: 14 mar. 2018.

DESIGN COUNCIL. Design for public good. 03 jun 2013. Disponível em:<http://www.designcouncil. 
org.uk/resources/report/design-public-good >. Acesso em: 18 jun. 2016.

DEURSEN, Alexander Van; et all. The compoundness and sequentiality of digital inequality. International Journal of Communication, 11, 452-473. 2017. Disponível em: <http://ijoc.org/ index.php/ijoc/article/view/5739/1911 >. Acesso em: 28 jan. 2018.

HELLER, Steven; TALARICO, Rita. An education manifesto for Icograda. In: Icograda Design Education Manifesto. p. 82-84, 2011. Disponível em: <http://www.ico-d.org/database/files/ library/IcogradaEducationManifesto_2011.pdf. Acesso em: 25 jan 2017.

HELSPER, E. J. Desigualdades no letramento digital:definições, indicadores, explicações e implicações para políticas públicas. in: TIC Domicílios 2015, p. 33-43, 2016. Disponível em: <http://cgi.br/media/docs/publicacoes/2/TIC_Dom_2015_LIVRO_ELETRONICO.pdf >. Acesso em: 23 fev. 2017.

HOBI . Guilherme. Design de serviços para o setor público: a importância desta abordagem para a inovação em serviços públicos. Disponível em:<http://www.up.edu.br/blogs/fulldesign/designde-servicos-para-o-setor-publico-a-importancia-desta-abordagem-para-a-inovacao-em-servicos-pu blicos/ >. Acesso 24 fev 2017.

IBGE. Censo 2010. Disponível em: <http://www.ibge.gov.br/home/mapa_site/mapa_site.php>. Acesso em: 30 jan 2017.

ICOGRADA. Icograda Design Education Manifesto 2011. Disponível em: <http://www.ico-d.org/ database/files/library/IcogradaEducationManifesto_2011.pdf. Acesso em: 25 jan 2017.

JÚDICE, Andrea C. B. Design for Hope: Designing Health Information in Villa Rosário. 2014. 295p Tese - Aalto University. Helsinque:Finlândia.

LEON, Ethel; MONTMORE, Marcello. Brasil. in:FERNÁNDEZ, Silvia; BONSIEPE, Gui (orgs.) Historia del diseño en América Latina y el Caribe. São Paulo: Ed. Blucher, 2008. p. 62-86.

LÖBACH, Bernd. Design Industrial: Bases para configuração dos produtos industriais. Tradução Fred dy Van Camp. Rio de Janeiro: Edgard Blücher, 2001.

MAFFEI, Stefano; MORTATI, Marzia; VILLARI, Beatrice. Making/Design Policies Together. 10th European Academy of Design Conference - Crafting the Future. 2013. Disponível em: <https://www.academia.edu/3339670/Making_Design_policies_together>. Acesso em: 08 ago, 2017. Disponível em: <http://ticeduca.ie.ul.pt/atas/pdf/376.pdf >. Acesso em: 12 jun 2017

MIETTINEN, Satu; SARANTOU, Melanie. Social Design for Services Framework: Capturing Service Design for Development Framework. In: Design Management Academy Conference. Anais eletrônicos. Hong Kong: Vol. 3 p. 917-930. 2017. Disponível em: <http://designmanagementacade my.com/dma2017/>. Acesso em: 21 jan. 2018.

NORMAN, Don. The Future of Design: When you come to a fork in the road, take it. jnd.org. 23 mar, 2016. Disponível em: <https://www.jnd.org/dn.mss/the_future_of_design.html >. Acesso em: 12 de jul. 2017.

PATROCINIO, Gabriel. Gabriel Patrocínio fala sobre políticas públicas de design no Brasil. Entrevista [jun. 2013]. Entrevistador: BAUER, Juliana. 04 set 2013. Entrevista concedida a DesignBrasil. Disponível em: <http://www.designbrasil.org.br/entre-aspas/gabriel-patrocinio-falasobre-politicas-publicas-de-design-no-brasil/ >. Acesso em: 17 Jul 2017 
PORTINARI, Denise Berruezo; NOGUEIRA, Pedro Caetano. Por um design político. Revista Estudos em Design. Rio de Janeiro: v. 24 n. 3 p. 32 - 46, 2016. Disponível em: <https://estudosemdesign. emnuvens.com.br/design/article/view/379>. Acesso em: 21 mar. 2018.

ROVAI, Renato. Banda Larga no Brasil, o papel do Estado e possibilidades de crescimento econômico e desenvolvimento humano. Revista Communicare Volume 14 - № 2 - págs. 110-123. 2014. Disponível em: <https://casperlibero.edu.br/wp-content/uploads/2016/01/Banda-Largano-Brasil-o-papel-do-Estado-e-possibilidades-de-crescimento-econ\%C3\%B4mico-e-desenvolvimen to-humano.pdf> Acesso em: 20 de fev. 2017.

SARGEANT, Richard. Digital strategy, Measurement and analytics. GOV.UK Blog. 17 Jan. 2013. Disponível em:<https://gds.blog.gov.uk/2013/01/17/gov-transaction-costs-behind-data/> Acesso: 22 mar 2017.

SOCIAL DESIGN NOTES. 100+ Years of Design Manifestos. Disponível em: <https://backspace.com/ notes/2009/07/design-manifestos.php>. Acesso em: 21 mar. 2018.

STICKDORN, Marc; SCHNEINER, Jackob (org). Isto é Design Thinking de Serviços. Porto Alegre : Ed. Bookman, 2014.

TCU. Política Pública de Inclusão Digital. Tribunal de Contas da União. Brasil, 2015. Disponível em: <http://portal.tcu.gov.br/biblioteca-digital/politica-publica-de-inclusao-digital.htm>. Acesso em: 14 de nov. 2017.

UNESCO. Sociedade digital: hiatos e desafios da inclusão digital na América Latina e o Caribe. Livro Eletrônico, 2017. Disponível em: <https://www.cgi.br/media/docs/publicacoes/8/Policy Papers-Ministros-BrechaDigital-PT.pdf>. Acesso em: 14 mar. 2018.

WDO. Definition of Industrial Design. 2015. World Design Organization. Disponível em: <http://wdo.org/about/definition/>. Acesso em: 25 jan 2017.

YAMAMOTO, Ricardo. Papel Social do Designer Gráfico: Realidades e Premissas. Trabalho de Conclusão de Curso. FAU USP. São Paulo, 2014. Disponível em: <hhttp://www.fau.usp.br/ fauforma/2015/assets/ricardo_yamamoto.pdf>. Acesso em: 20 de fev. 2017.

XAVIER, Antonio Carlos dos Santos. Letramento digital e ensino. In: SANTOS, Carmi Ferraz; MENDONÇA, Márcia (Org.) Alfabetização e letramento: conceitos e relações. Belo Horizonte: Autêntica, 2007. p. 133-148. Disponível em: <http://pacto.mec.gov.br/images/pdf/Formacao/ Alfabetizacao_letramento_Livro.pdf>. Acesso em: 21 set. 2016. 